\title{
Prevalence of neonatal hyperbilirubinemia and its association with glucose-6-phosphate dehydrogenase deficiency and blood type incompatibility in sub-Saharan Africa: a systematic review and meta-analysis
}

Yared Asmare Aynalem ( $\square$ yaredasmare123@gmail.com )

Debre Birhan University https://orcid.org/0000-0002-3005-2296

Getaneh Baye Mulu1

Debre Birhan University

\section{Tadesse Yirga Akalu}

Debre Markos University

Wondimeneh Shibabaw Shiferaw

Debre Birhan University https://orcid.org/0000-0003-4348-591X

Systematic Review

Keywords: hyperbilirubinemia, blood type incompatibility, glucose-6-phosphate dehydrogenase, subSaharan Africa

Posted Date: May 18th, 2020

DOI: https://doi.org/10.21203/rs.3.rs-29475/v1

License: (c) (i) This work is licensed under a Creative Commons Attribution 4.0 International License. Read Full License 


\section{Abstract}

Background: Severe indirect hyperbilirubinemia is a silent cause of newborn disease and death worldwide. However, studies of the disease in sub-Saharan Africa are highly variable with respect to its prevalence. Hence, this study aimed to estimate the overall magnitude of neonatal hyperbilirubinemia and its association with glucose-6-phosphate dehydrogenase (GP6D) deficiency and blood type incompatibility in sub-Saharan Africa.

Methods: PubMed, Scopus, Google Scholar, and the Cochrane Review were systematically searched online to retrieve hyperbilirubinemia-related articles. All observational studies reported the prevalence of hyperbilirubinemia in sub-Saharan Africa were included for analysis and excluded if the study failed to determine the desired outcome. The Preferred Reporting Items for Systematic Review and Meta-Analysis (PRISMA) guidelines were followed. Heterogeneity across the included studies was evaluated using the inconsistency index $\left(\mathrm{I}^{2}\right)$. Publication bias was examined by funnel plot and the Egger's regression test. The random-effect model was fitted to estimate the pooled prevalence of neonatal hyperbilirubinemia among patients in Sub Saharan Africa. The meta-analysis was performed using the STATA ${ }^{\text {TM }}$ version 14 software.

Results: A total of 30,486 studies were collected from the different databases and 10 articles were included for the final analysis. The overall magnitude of neonatal hyperbilirubinemia was $28.08 \%$ (95\% Cl: $(20.23,35.94))$ in sub-Saharan Africa. Neonates with G6PD deficiency were 2.42 times (95\% Cl: 1.64 , 3.56) more likely to develop hyperbilirubinemia as compared to infants with normal G6PD levels. Moreover, the risk of developing hyperbilirubinemia was 3.3 times $(95 \% \mathrm{Cl}: 1.96,5.72)$ higher among neonates that had a blood type that was incompatible with their mother's.

Conclusion: The failure to prevent and screen G6PD deficiency and blood type incompatibility with their mother's results in high burden of neonatal hyperbilirubinemia in sub-Saharan Africa. Therefore, early identification and care strategies should be developed to the affected neonates with G6PD deficiency and blood type incompatibility with their mother's to address long-term medical and scholastic damages among those exposed to severe hyperbilirubinemia

\section{Background}

Neonatal hyperbilirubinemia (i.e., jaundice) is a common and frequently benign condition that afflicts many infants in the first week of life. It is caused by the accumulation of bilirubin in the skin, which is created from biliverdin, a breakdown product of heme. Over $50 \%$ of newborns get jaundice in the first few days of life, and $60 \%-80 \%$ leads to unpreventable condition in newborns worldwide (1). Elevated levels of conjugated bilirubin (i.e., conjugated bilirubin level being $\geq 20 \%$ of the total serum bilirubin) are always pathologic and occur due to intra- or extrahepatic obstruction of the biliary tract. Moreover, it is the most common reason for neurological sequelae related to hyperbilirubinemia (2). The most significant among the long-term complications of hyperbilirubinemia is kernicterus, which is a type of brain damage that 
leads to choreoathetosis, sensorineural hearing loss, dental enamel dysplasia, paralysis of upward gaze, hypotonia, and a delay in the acquisition of motor skills, with a significant risk of neonatal death (3).

The prevalence of hyperbilirubinemia in the neonates of sub-Saharan Africa is somewhat inconsistent in the current literature, with rates ranging from $4-45.8 \%$ (4-7). That said, the burden of this condition on medical systems in developed and developing nations is significant (1). There are many risk factors that can predispose infants to hyperbilirubinemia, including jaundice observed in the first 24 hours, blood group incompatibility, other known hemolytic disease, elevated end-tidal carbon dioxide, gestational age of 35-36 weeks, sibling received phototherapy, cephalohematoma, significant bruising, excessive weight loss, isoimmune hemolytic disease, glucose-6-phosphate dehydrogenase (G6PD) deficiency, asphyxia, temperature instability, sepsis, acidosis, and albumin $<3 \mathrm{~g} / \mathrm{dl}(2,7,8)$. More than any other risk factors, G6PD deficiency and blood group incompatibility are the most significant contributing causes for neurotoxicity (2). More than $70 \%$ of hyperbilirubinemia cases are due to either idiopathic neonatal hepatitis or biliary atresia (3).

Although G6PD deficiency and blood group incompatibility are widely regarded as risk factors for hyperbilirubinemia, the literature does show some inconsistencies (7-14). For instance, several studies from sub-Saharan African countries (7, 9-11) have indicated that G6PD deficiency and blood incompatibility are associated with an increased risk of neonatal jaundice. However, another study showed that they were not associated with jaundice (12). Given this variability and the lack of pooled representative data, we aimed to estimate the pooled burden of neonatal hyperbilirubinemia in countries of sub-Saharan Africa. Moreover, we attempted to identify its association with G6PD deficiency and blood type incompatibility in this region. This data will aid healthcare professionals in assessing the prevalence of hyperbilirubinemia in their population and hopefully allow them to properly allocate resources to combat this neonatal affliction.

\section{Methods}

\subsection{Data Sources and Literature Search Strategy}

This systematic review and meta-analysis was reported according to the Preferred Reporting Items for Systematic Reviews and Meta-Analyses (PRISMA) guidelines. Pertinent published articles were searched independently and systematically by the authors in the following electronic databases: PubMed, Google Scholar, African Journals Online, Scopus, and others. In addition, a manual search of gray literature was performed to find other significant studies. The searches were limited to full text, open access articles with human subjects that were written in any language. Authors were contacted for full texts of their articles through e-mail, if necessary. The search was conducted using the following terms and phrases: "magnitude neonatal hyperbilirubinemia," "neonatal jaundice," "glucose-6-phosphate dehydrogenase deficiency," "blood type incompatibility," and "sub-Saharan Africa". Boolean operators like "and" and "or" were used to combine search terms. Particularly, to fit the advanced PubMed database, the following 
search strategy was used: ("magnitude neonatal hyperbilirubinemia" OR "glucose-6-phosphate dehydrogenase deficiency" OR "blood type incompatibility") AND ("sub-Saharan Africa").

\subsection{Eligibility Criteria}

\subsubsection{Predefined inclusion criteria}

Studies were included for further analysis if they conformed to the following criteria:(1) All observational studies reported the prevalence of hyperbilirubinemia (2) the study setting was somewhere in subSaharan Africa,(3) The study participants were newborns with severe hyperbilirubinemia, (4) publication condition: all published articles, (5) language: all articles published in English language was included,

(6) the article was an observational study, a retrospective or prospective cohort study, or a cross-sectional study and (7) the study was published before April 10, 2019.

\subsubsection{Exclusion Criteria}

Studies were excluded from this systematic review and meta-analysis if they fulfilled one of the following:(1) we were unable to access the full text articles after two emails to the principal investigator, (2) a study was a duplicate of a previously identified study,(3) the study had a poor quality score as per the inclusion criteria and, (4) the study failed to determine the desired outcome.

\subsubsection{Type of exposure}

In this meta-analysis, G6PD deficiency and blood type incompatibility were considered the exposure variables to estimate their effects on neonatal hyperbilirubinemia.

2.2.3.1. Outcome of interest: prevalence of neonatal hyperbilirubinemia.

\subsection{Methods for data extraction and quality assessment}

We used a Microsoft Excel standardized data extraction form to extract the data. The following information was extracted from each incorporated study: the name of the first author, publication year, country name, study design, associated factors, sample size, final included sample size', response rate, study settings, risk estimate (Odds Ratio), and the $95 \%$ confidence interval (Cl). Data extraction from source documents was done independently by all investigators. Disagreements were resolved by consensus. The quality of the included studies was evaluated by using the Newcastle-Ottawa Scale (NOS) (13). Specifically, NOS assessed the sample representativeness and size, the comparability between participants, how neonatal hyperbilirubinemia was ascertained, and the statistical quality of each study. Studies were included for further analysis if they scored $\geq 5$ out of 10 points in three domains of ten modified NOS components.

\subsection{Data processing and analysis}


Data were extracted from Microsoft Excel and analyzed using STATA Version 14 statistical software and forest plots that showed combined estimates with a $95 \% \mathrm{Cl}$. The overall pooled prevalence was estimated by random effect meta-analysis (14). Heterogeneity was assessed by computing $p$ values for the Cochrane Q-test and inconsistency index $\left(R^{2}\right)(15)$. Given that we found significant heterogeneity among the studies ( $R=81.1 \%, p=0.001)$, a random-effects meta-analysis model was used to estimate the pooled effect. Meta-regression analysis was performed to explore the possible source of heterogeneity. We also carried out a leave-one-out sensitivity analysis to assess how individual studies impacted heterogeneity. Publication bias was assessed using a funnel plot and the Egger's regression test (14). For the second outcome, the odds ratio was used to ascertain the association between determinant factors and outcome variables in the included articles.

\section{Results}

\section{Search process}

A total of 30,486 studies were collected from the aforementioned databases. After removing duplicates (n $=29,927)$, a total of 559 studies were retrieved. Of which, 486 were rejected just by reading the titles of the articles. Of the remaining 73 studies, 31 were excluded after reading the abstracts. Full text copies of the remaining 48 studies that met, or potentially met, the inclusion criteria were assessed. After further screening, 10 papers were retained for further analysis, and all, except one (French) were published in English. Based on the predefined criteria and quality assessment, only 10 articles were included in the final analysis (Figure 1).

\section{Characteristics of included studies}

The pooled prevalence of neonatal hyperbilirubinemia in sub-Saharan Africa was assessed using 10 studies involving a total of 12,327 participants. The prevalence of hyperbilirubinemia in these studies ranged from $4.9 \%$ (4) to $44.9 \%$ (9), and most used a cross-sectional study design. The minimum sample size was 91 participants in a study conducted at Awolowo University, Nigeria (16), while the largest sample size was 5229 participants from Nigeria (11). All studies involved populations from sub-Saharan Africa, with six involving participants from Nigeria $(6,8,10,11,16,17)$, two from Ethiopia $(7,9)$, and one each from Zimbabwe (5), and Congo (4). Regarding the sampling technique employed, six of the studies (7-9, 16-18) used consecutive sampling to select study participants. However, the other studies did not report their sampling methods (Table 1).

Table 1. Baseline characteristics of the studies used to assess the pooled prevalence of neonatal hyperbilirubinemia in sub-Saharan Africa. 


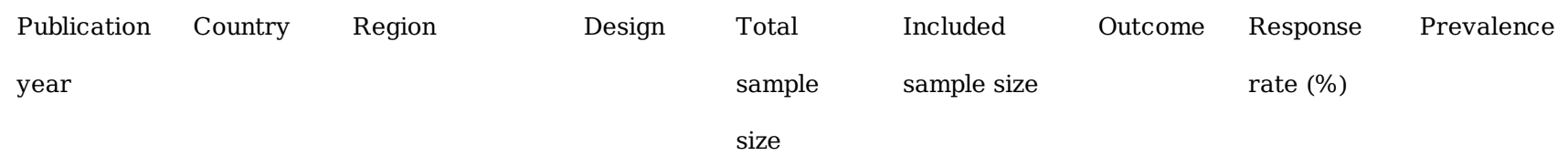

\begin{tabular}{|c|c|c|c|c|c|c|c|c|}
\hline 2019 & Ethiopia & Tigray & $\begin{array}{l}\text { Cross- } \\
\text { sectional }\end{array}$ & 209 & 209 & 78 & 100 & 37.3 \\
\hline 2018 & Ethiopia & Addis Ababa & $\begin{array}{l}\text { Cross- } \\
\text { sectional }\end{array}$ & 356 & 356 & 160 & 100 & 44.9 \\
\hline 2011 & Nigeria & $\begin{array}{l}\text { Southeast } \\
\text { Nigeria }\end{array}$ & $\begin{array}{l}\text { Cross- } \\
\text { sectional }\end{array}$ & 457 & 457 & 160 & 100 & 35 \\
\hline 2015 & Nigeria & Ibadan & $\begin{array}{l}\text { Cross- } \\
\text { sectional }\end{array}$ & 232 & 232 & 79 & 100 & 34.1 \\
\hline 2018 & Nigeria & Cosmopolitan & Cohort & 1106 & 1106 & 159 & 100 & 15.3 \\
\hline 2014 & Nigeria & $\begin{array}{l}\text { Awolowo } \\
\text { University }\end{array}$ & Cohort & 644 & 91 & 129 & 99.3 & 20 \\
\hline 2018 & Nigeria & $\begin{array}{l}\text { Enugu State } \\
\text { University }\end{array}$ & Cohort & 1920 & 1920 & 480 & 100 & 25 \\
\hline 2014 & Congo & Congo & $\begin{array}{l}\text { Cross- } \\
\text { sectional }\end{array}$ & 2410 & 2410 & 120 & 100 & 4.9 \\
\hline 1997 & Zimbabwe & Zimbabwe & Cohort & 120 & 110 & 50 & 91.7 & 45.4 \\
\hline
\end{tabular}

\section{Magnitude of neonatal hyperbilirubinemia}

The overall random effects estimate for the level of neonatal hyperbilirubinemia across sub-Saharan Africa was $28.08 \%$ (95\% Cl: $(20.23,35.94))$ (Figure 2). Our test statistics indicated a high level of heterogeneity $\left(I^{2}=83.2 \%, p<0.001\right)$ and the Eggers' test showed a significant publication bias $(p<$ 0.036).

\section{Subgroup analysis}

We performed a subgroup analysis using study design and the location of the included studies. Our subgroup analysis based on study location showed that the highest pooled prevalence was observed 
from studies done in Ethiopia (41.4\%; 95\% Cl: 33.9, 48.8)(Figure 3). But no any difference in the level of neonatal hyperbilirubinemia with study design (Figure 4).

\section{Meta-regression analysis}

To identify the sources of heterogeneity in this study, meta-regression analysis was performed by considering the year of publication and sample size. However, our results showed that those covariates were not significantly associated with the presence of heterogeneity (Table 2).

Table 2. Meta-regression analysis using year of publication and sample size for the included studies.

\begin{tabular}{llllll}
\hline Covariate & Coefficient & Standard error & t value & p value & $\overline{95 \% \text { CI }}$ \\
\hline Sample size & -0.0033 & 0.0026 & 1.27 & 0.24 & $0.001,0.002$ \\
Publication year & -0.46 & 0.69 & -0.67 & 0.52 & $-2.06,1.13$ \\
\hline
\end{tabular}

\section{Publication bias and quality status}

Publication bias was evaluated by a funnel plot and the Egger's regression test. With respect to the former, publication bias is represented as significant asymmetry in a funnel plot. As depicted in Figure 5, there was a significant amount of asymmetry in our funnel plot and thus there was some publication bias. The Egger's regression test confirmed this result with a $p$ value $=0.036$. The quality assessment for each study is shown in Supplementary file.

\section{Sensitivity analysis}

We performed a sensitivity analysis to assess the weight of every study on the pooled effect size. Our analyses using the Der Simonian-Laird random-effects model revealed that there was no single study that affected the overall magnitude neonatal hyperbiliruminemia in sub-Saharan Africa(Figure 6).

\section{The association between G6PD deficiency and neonatal hyperbilirubinemia}

The association between neonatal hyperbilirubinemia and G6PD deficiency was reported in four articles $(6,16,19)$. The pooled odds ratio from these studies was 2.42 (95\% Cl: $1.64,3.56)$, indicating that the likelihood of hyperbilirubinemia was 2.42 times higher in neonates with a G6PD deficiency than those with normal G6PD levels (Figure 7).

\section{The association between blood type incompatibility and neonatal hyperbilirubinemia}

Blood type incompatibility was another contributing factor for neonatal hyperbilirubinemia and their connection was reported in five studies included in our analyses $(6,7,9-11)$. The pooled odds ratio was 3.3 (95\% Cl: $1.96,5.72)$, suggesting that the risk of developing hyperbilirubinemia was 3.3 times higher 
among neonates with an incompatible blood type as compared to blood type-compatible infants (Figure 8).

\section{Discussion}

Neonatal hyperbilirubinemia remains the principal reason of morbidity and mortality in resource-limited nations(4-7). The prevalence is also variable across different studies (4-7). Inconsistence estimates is reported in the association with G6PD deficiency $(2,7,8)$ and blood type incompatibility $(2,7,8)$. So that, this meta-analysis determined the pooled prevalence of neonatal hyperbilirubinemia and its association with G6PD deficiency and blood type incompatibility in sub-Saharan Africa using ten studies.

The overall pooled estimate for the prevalence of hyperbilirubinemia was $28.08 \%$ (95\% Cl: (20.23, 35.94)). This is consistent with the rates of neonatal hyperbilirubinemia in the United States of America (20). However, our finding is higher than that found in a previous meta-analysis (21). In contrast, the prevalence of hyperbilirubinemia found in our study was substantially lower than that found in previous systematic reviews carried out in Pakistan (22), Myanmar (23) and global burden diseases GBD $(24,25)$. These differences might be the result of different diagnostic standards for neonatal hyperbilirubinemia, early diagnosis and treatment in developed countries, and the early discharge of healthy late-preterm and full-term newborns.

The prevalence of neonatal hyperbilirubinemia varied greatly in the included studies, ranging from $4.9 \%$ (4) to $44.9 \%$ (9). However, our subgroup analysis based on study location showed that the highest pooled prevalence was observed from studies done in Ethiopia $(41.4 \% ; 95 \% \mathrm{Cl}: 33.9,48.8)$. A possible explanation for this variation could be the differences in healthcare facilities.. With emerging an inexpensive technology, the developed nations prevention and treatment of neonatal hyperbilirubinemia can more feasibly reach those at risk as compare to resource-limiting settings. Additionally,developed nations may have a better screening strategy of postnatal hemolysis and management of idiopathic etiologies which may help to reach both a near eradication of mortality related with jaundice and reduces in its impairment.

In this study, the odds of an infant getting hyperbilirubinemia was 2.4 times higher for those neonates with a G6PD deficiency than those with normal G6PD levels. This is in line with studies done in different countries $(18,23,26-28)$. G6PD deficiency may be linked to hyperbilirubinemia because G6PD is the main source for NADPH in red blood cells, which is important for antioxidant defense. Those neonates that are deficient in G6PD are susceptible to oxidant-induced hemolysis and heme catabolism that produces bilirubin - the precipitating factor in hyperbilirubinemia (29).

This study also noted that the likelihood of having hyperbilirubinemia was higher among neonates with blood group incompatibility. Neonates with blood group incompatibility were 3.3 times more likely to have hyperbilirubinemia as compared to patients with a compatible blood type. This is supported by a number of previous studies $(23,30)$. This could be due to hemolysis that occurs when maternal immunoglobulin 
$\mathrm{G}$ anti-A or anti-B antibodies cross the placenta and attach to the opposite antigen site on the neonatal red cell, which results in increase heme catabolism that increases the production bilirubin(31)

The implication of the current finding is stated as follows; estimating the prevalence of neonatal hyperbilirubinemia and its association with G6PD deficiency and blood type incompatibility will help to mobilize the national leadership to initiate actions and embed proven systems, policies, and programs to reduce jaundice-related newborn mortality and disabilities. The health care professional will also include neonates born with glucose-6-phosphate dehydrogenase deficiency and blood type incompatibility as Every Newborn Action Plan promotion of maternal and newborn care and essential newborn care for better care of neonates with jaundice which helps better neonatal survival, improved long-term development, and decrease disability. It will also alarm them for national identification of all blood type incompatible woman before or during pregnancy and with coordinated obstetric and neonatal care.

\section{Strengths and limitations of the study}

As far as we know this is the first meta-analysis which has been done in sub-Saharan Africa. This study was conducted with the use of an inclusive search strategy to incorporate the studies involving African patients. All of the included studies had high methodological quality based on our NOS assessments. Despite this, our study had several limitations. First, most of the studies used for this analysis had a small sample size, which could have a significant effect on the estimated prevalence of neonatal hyperbilirubinemia. Moreover, this meta-analysis represented only studies from five countries, which may be an underrepresentation for the region of sub-Saharan Africa.

\section{Conclusion}

This study noted that neonatal hyperbilirubinemia in sub-Saharan Africa was quite common. This study also revealed that neonatal hyperbilirubinemia is associated with G6PD deficiency and blood type incompatibility. Based on our findings, we suggest that all neonates with hyperbilirubinemia be assessed for G6PD deficiency and blood type compatibility to identify the most likely to contract the disease. Furthermore, additional research is needed to identify other associated factors for the development of neonatal hyperbilirubinemia

\section{Abbreviations}

Cl: confidence interval; G6PD; glucose-6-phosphate dehydrogenase, NOS: Newcastle-Ottawa Scale; OR; odds ratio; PRISMA: Preferred Reporting Items for Systematic Reviews and Meta-Analyses

\section{Declarations}

Acknowledgements 
We would like to thank to Doctor Ryan Bell (CEO and Chief Editor Excision Editing) whose assistance was invaluable to the completion of the study and who have made an extensive edition in our manuscript.

\section{Available data and materials}

The data analyzed during the current meta-analysis is available from the corresponding author upon reasonable request.

\section{Authors' contributions}

YAA conceived and designed the study. YAA and WSS established the search strategy. WSS, TYA, and GBM wrote the review. All authors read and approved the final manuscript.

\section{Competing interest}

The authors declare that they have no competing interests.

\section{Funding}

The authors have also declared that they received no financial support in the research, authorship, and publication of this article.

\section{Consent for publication}

Not applicable

\section{References}

1. Olusanya BO, Kaplan M, Hansen TW. Neonatal hyperbilirubinaemia: a global perspective. The Lancet Child \& Adolescent Health. 2018;2(8):610-20.

2. Pace EJ, Brown CM, DeGeorge KC. Neonatal hyperbilirubinemia: an evidence-based approach. J Fam Pract. 2019;68:E4-E11.

3. Wright CJ, Posencheg MA. Neonatal Hyperbilirubinemia. Fundamentals of Pediatric Surgery: Springer; 2011. p. 561-6.

4. Mutombo AK, Mukuku O, Kabulo BK, Mutombo AM, Ngeleka AM, Mutombo JD, et al. Ictères pathologiques du nouveau-né à I'hôpital Bonzola de Mbuji-Mayi, République Démocratique du Congo. The Pan African medical journal. 2014;19.

5. Wolf M, Beunen G, Casaer P, Wolf B. Extreme hyperbilirubinaemia in Zimbabwean neonates: neurodevelopmental outcome at 4 months. European journal of pediatrics. 1997;156(10):803-7.

6. Osuorah CD, Ekwochi U, Asinobi IN. Clinical evaluation of severe neonatal Hyperbilirubinaemia in a resource-limited setting: a 4-year longitudinal study in south-East Nigeria. BMC pediatrics. 2018;18(1):202. 
7. Lake EA, Abera GB, Azeze GA, Gebeyew NA, Demissie BW. Magnitude of Neonatal Jaundice and Its Associated Factor in Neonatal Intensive Care Units of Mekelle City Public Hospitals, Northern Ethiopia. International journal of pediatrics. 2019;2019.

8. Onyearugha C, Onyire B, Ugboma H. Neonatal jaundice: prevalence and associated factors as seen in Federal Medical Centre Abakaliki, Southeast Nigeria. J Clin Med Res. 2011;3(3):40-5.

9. Kassa R, Gudeta H, Assen Z, Demlew T, Teshome G. Neonatal Hyperbilirubinemia: Magnitude and Associated Etiologic Factors among Neonates Admitted at Tikur Anbessa Specialized Hospital, Ethiopia. J Preg Child Health. 2018;5(384):2.

10. Diala UM, Wennberg RP, Abdulkadir I, Farouk ZL, Zabetta CDC, Omoyibo E, et al. Patterns of acute bilirubin encephalopathy in Nigeria: a multicenter pre-intervention study. Journal of Perinatology. 2018;38(7):873-80.

11. Emokpae AA, Mabogunje CA, Imam ZO, Olusanya BO. Heliotherapy for neonatal hyperbilirubinemia in Southwest, Nigeria: a baseline pre-intervention study. PloS one. 2016;11(3).

12. Sgro M, Campbell D, Shah V. Incidence and causes of severe neonatal hyperbilirubinemia in Canada. Cmaj. 2006;175(6):587-90.

13. G. A. Wells, B. Shea, D. O'Connell et al., NewCastle-Ottawa Quality Assessment Scale-Case Control Studies, Belia Vida Centre, Namibia, 2017.

14. Borenstein $M$, Hedges LV, Higgins JP, Rothstein HR. A basic introduction to fixed-effect and randomeffects models for meta-analysis. Research synthesis methods. 2010;1(2):97-111.

15. Rücker G, Schwarzer G, Carpenter JR, Schumacher M. Undue reliance on I 2 in assessing heterogeneity may mislead. BMC medical research methodology. 2008;8(1):79.

16. Badejoko BO, Owa JA, Oseni SB, Badejoko O, Fatusi AO, Adejuyigbe EA. Early neonatal bilirubin, hematocrit, and glucose-6-phosphate dehydrogenase status. Pediatrics. 2014;134(4):e1082-e8.

17. Farouk ZL, Muhammed A, Gambo S, Mukhtar-Yola M, Umar Abdullahi S, Slusher TM. Follow-up of children with kernicterus in kano, nigeria. Journal of tropical pediatrics. 2018;64(3):176-82.

18. Olusanya BO, Osibanjo FB, Slusher TM. Risk factors for severe neonatal hyperbilirubinemia in low and middle-income countries: a systematic review and meta-analysis. PloS one. 2015;10(2).

19. Wong F, Boo N, Othman A. Risk factors associated with unconjugated neonatal hyperbilirubinemia in Malaysian neonates. Journal of tropical pediatrics. 2013;59(4):280-5.

20. Yu T-C, Nguyen C, Ruiz N, Zhou S, Zhang X, Böing EA, et al. Prevalence and burden of illness of treated hemolytic neonatal hyperbilirubinemia in a privately insured population in the United States. BMC pediatrics. 2019;19(1):53.

21. Slusher TM, Zamora TG, Appiah D, Stanke JU, Strand MA, Lee BW, et al. Burden of severe neonatal jaundice: a systematic review and meta-analysis. BMJ paediatrics open. 2017;1(1).

22. Tikmani SS, Warraich HJ, Abbasi F, Rizvi A, Darmstadt GL, Zaidi AKM. Incidence of neonatal hyperbilirubinemia: a population-based prospective study in Pakistan. Tropical Medicine \& International Health. 2010;15(5):502-7. 
23. Thielemans L, Trip-Hoving M, Landier J, Turner C, Prins T, Wouda E, et al. Indirect neonatal hyperbilirubinemia in hospitalized neonates on the Thai-Myanmar border: a review of neonatal medical records from 2009 to 2014. BMC pediatrics. 2018;18(1):190.

24. Olusanya BO, Teeple S, Kassebaum NJ. The contribution of neonatal jaundice to global child mortality: findings from the GBD 2016 study. Pediatrics. 2018;141(2):e20171471.

25. Peeters B, Geerts I, Van Mullem M, Micalessi I, Saegeman V, Moerman J. Post-test probability for neonatal hyperbilirubinemia based on umbilical cord blood bilirubin, direct antiglobulin test, and $A B O$ compatibility results. European journal of pediatrics. 2016;175(5):651-7.

26. Liu H, Liu W, Tang $X$, Wang T. Association between G6PD deficiency and hyperbilirubinemia in neonates: a meta-analysis. Pediatric hematology and oncology. 2015;32(2):92-8.

27. Olusanya BO, Emokpae AA, Zamora TG, Slusher TM. Addressing the burden of neonatal hyperbilirubinaemia in countries with significant glucose-6-phosphate dehydrogenase deficiency. Acta paediatrica. 2014;103(11):1102-9.

28. BOZKURT Ö, YÜCESOY E, OĞUZ B, AKINEL Ö, Palali MF, ATAŞ N. Severe neonatal hyperbilirubinemia in the southeast region of Turkey. Turkish Journal of Medical Sciences. 2020;50(1):103-9.

29. Watchko J, Kaplan M, Stark A, Stevenson D, Bhutani V. Should we screen newborns for glucose-6phosphate dehydrogenase deficiency in the United States? Journal of Perinatology. 2013;33(7):499504.

30. Olusanya BO, Slusher TM. Infants at risk of significant hyperbilirubinemia in poorly-resourced countries: evidence from a scoping review. World Journal of Pediatrics. 2015;11(4):293-9.

31. Kaplan M, Hammerman C, Vreman HJ, Wong RJ, Stevenson DK. Hemolysis and hyperbilirubinemia in antiglobulin positive, direct $\mathrm{ABO}$ blood group heterospecific neonates. The Journal of pediatrics. 2010;157(5):772-7.

\section{Figures}




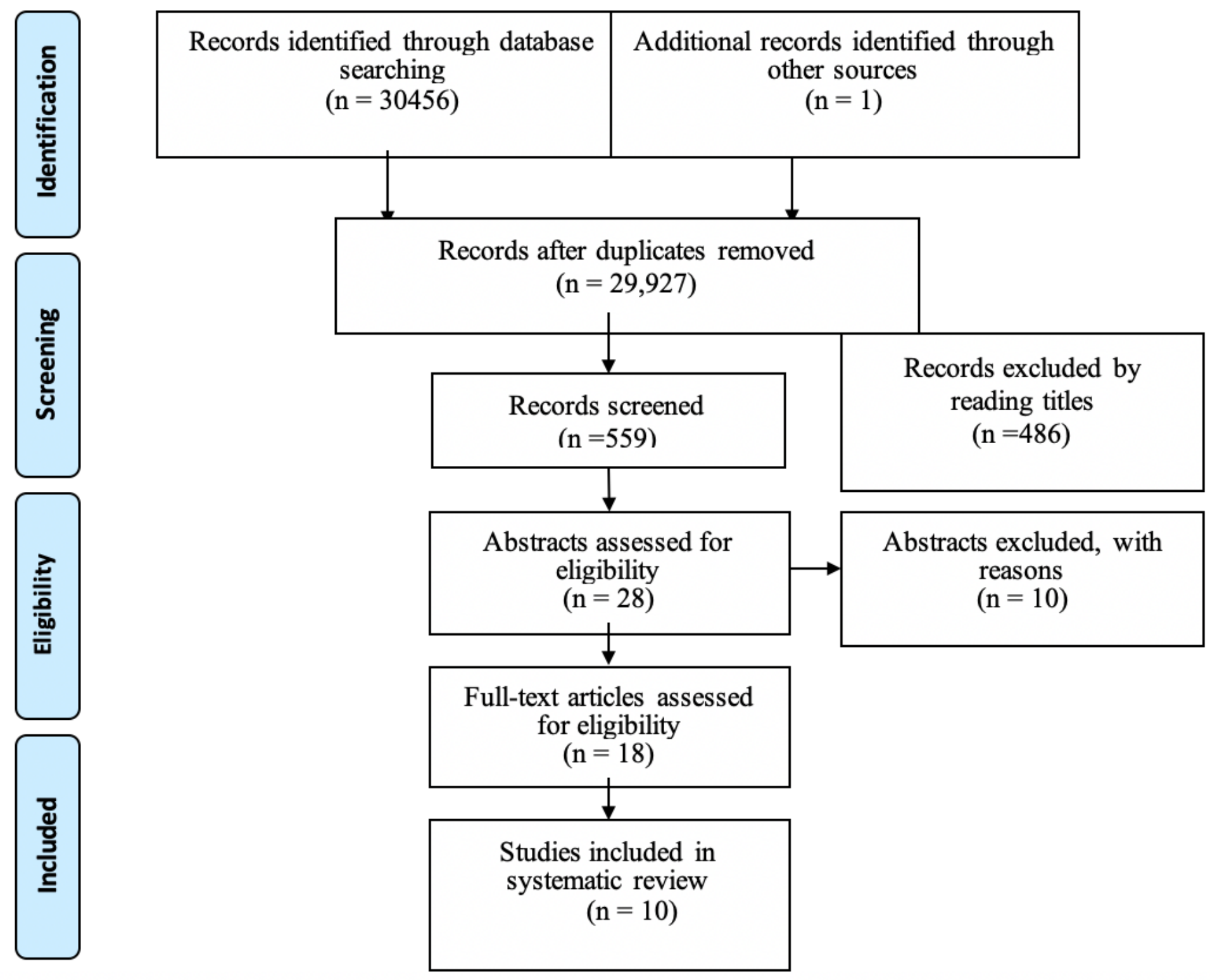

Figure 1

Flow chart of how research articles were searched and selected for analysis in this study. 
Author/year

Prevalence $(95 \% \mathrm{CI})$ Weight

Lake et al. (2019)

Onyearugha et al. (2011)

olorunso et al. (2015)

Diala et al. (2018)

Badejoko et al. (2014)

Emokpae et al. (2016)

Osuorah et al. (2018)

Mutombo et al. (2014)

Wolf et al. (1997)

Overall $(\mathrm{I}$-squared $=83.2 \%, \mathrm{p}=0.0001)$

NOTE: Weights are from random effects analysis

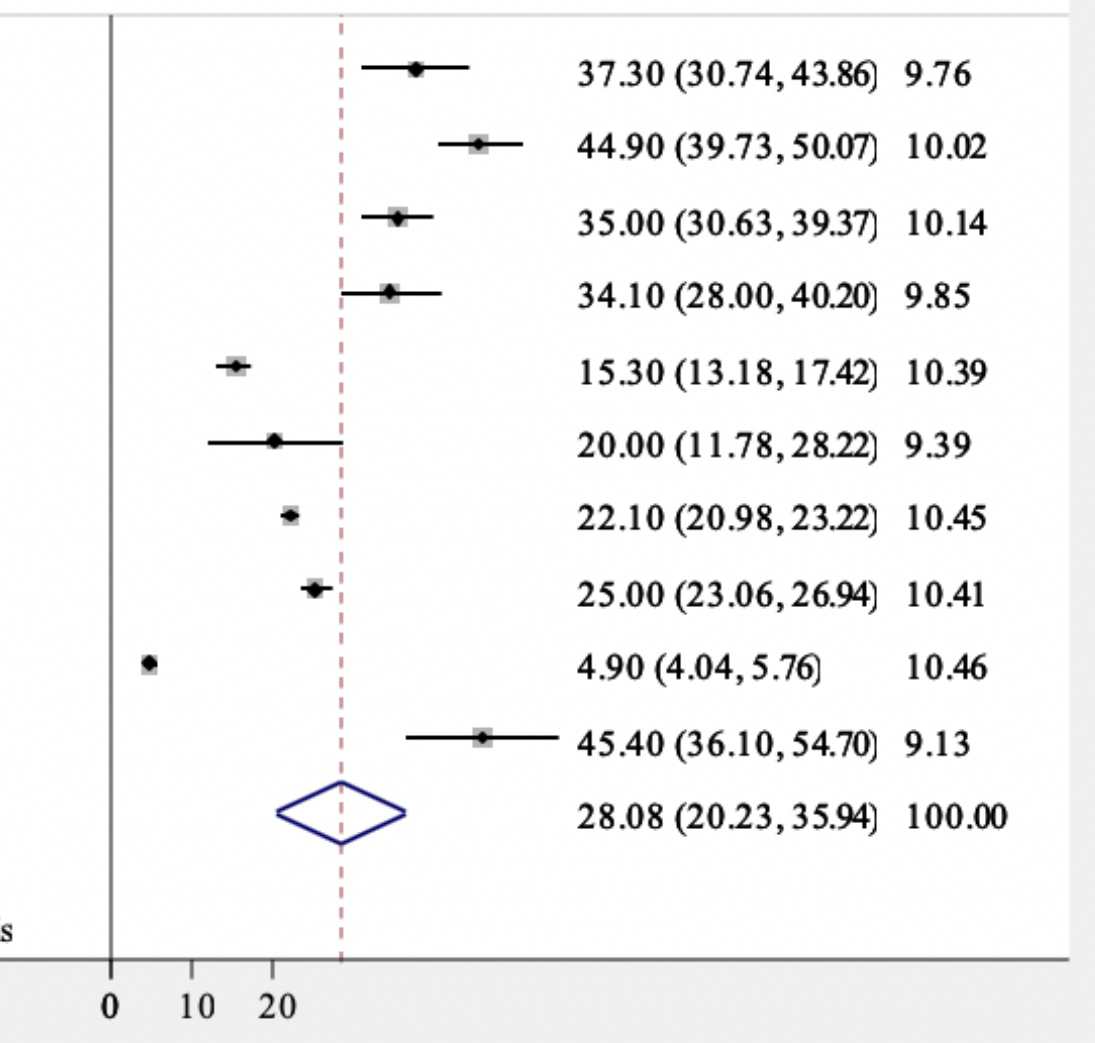

\section{Figure 2}

Prevalence of neonatal hyperbilirubinemia in sub-Saharan Africa. 
publication

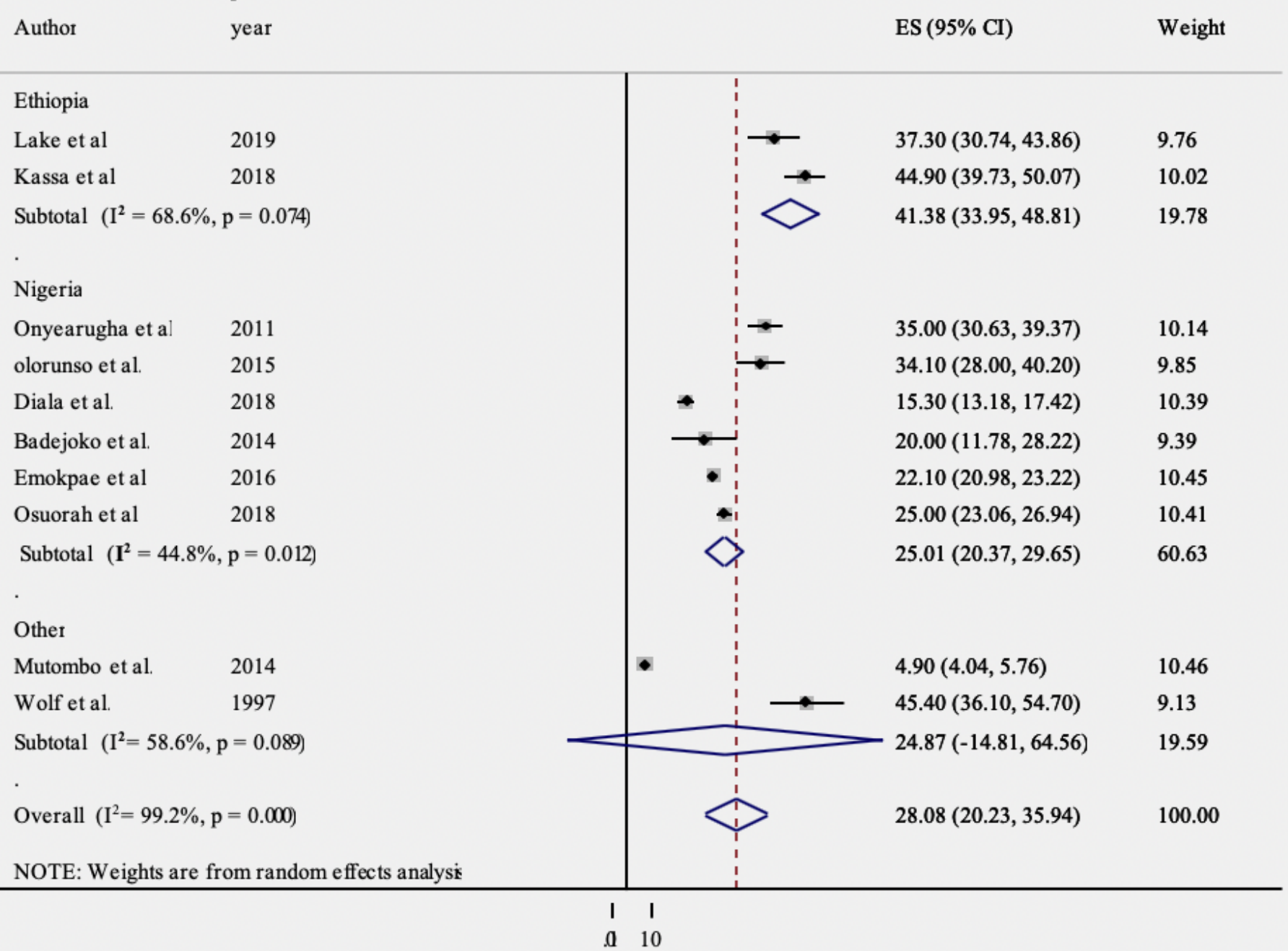

\section{Figure 3}

Subgroup analysis of the magnitude of neonatal hyperbilirubinemia based on study location. 


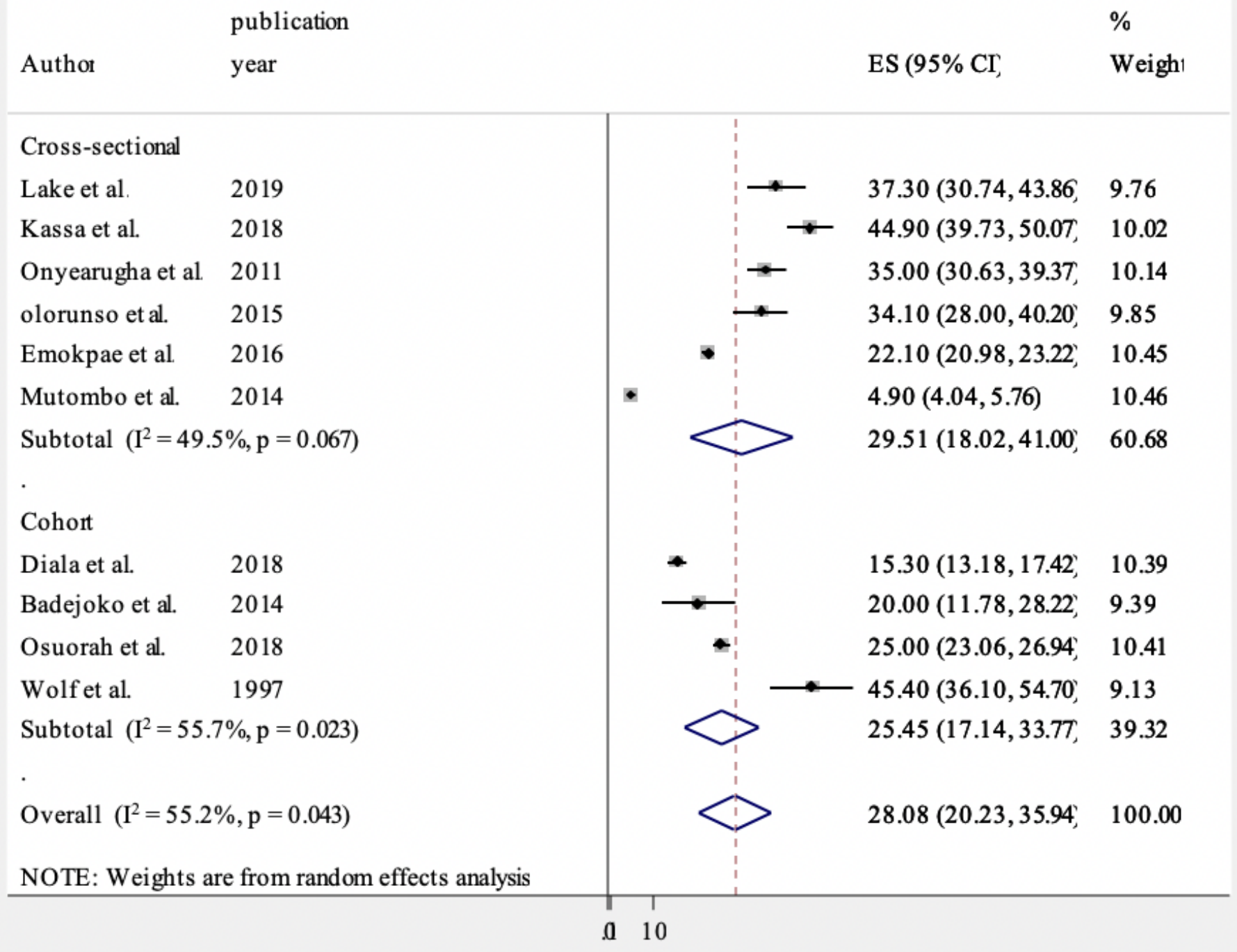

\section{Figure 4}

Subgroup analysis of the magnitude of neonatal hyperbilirubinemia based on study design. 


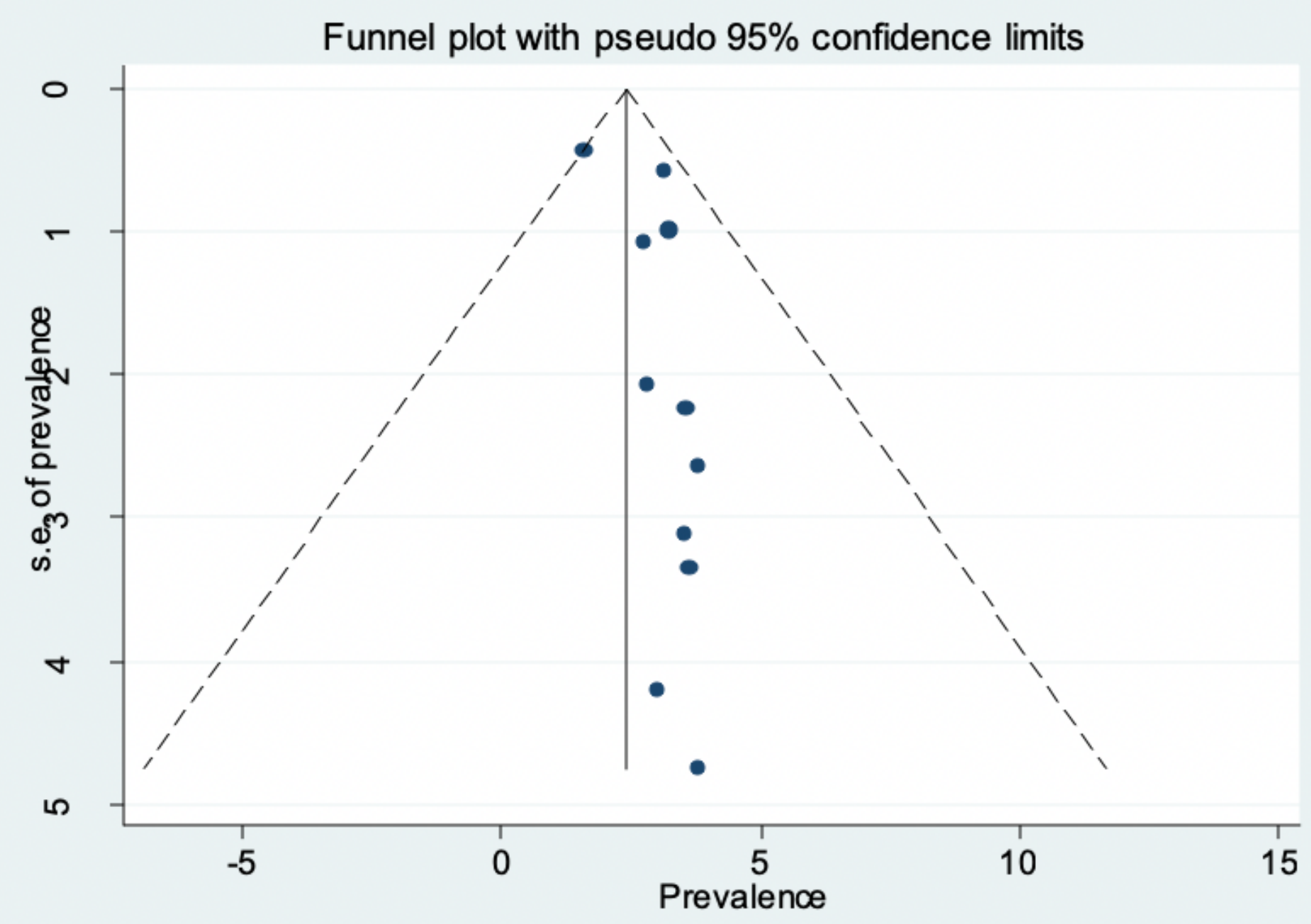

Figure 5

Funnel plot to determine publication bias among the included studies. 
Meta-analysis estimates, given named study is omitted

Kassa et al. (2018)

○

Onyearugha et al. (2011)

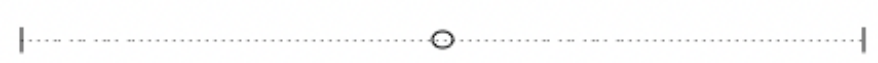

olorunso et al. (2015)

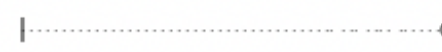

o

- 1

Diala et al. (2018)

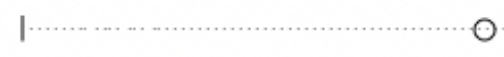

Badejoko et al. (2014)

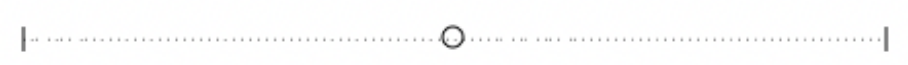

Wong et al. (2013)

Emokpae et al. (2016)

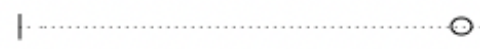

$\odot$

\section{....}

Osuorah et al. (2018)

1

O

Mutombo et al. (2014)

$1+\ldots$

Wolf et al. (1997)

0

\section{Figure 6}

Sensitivity analyses of the included studies. 
Woimoet al (2015)

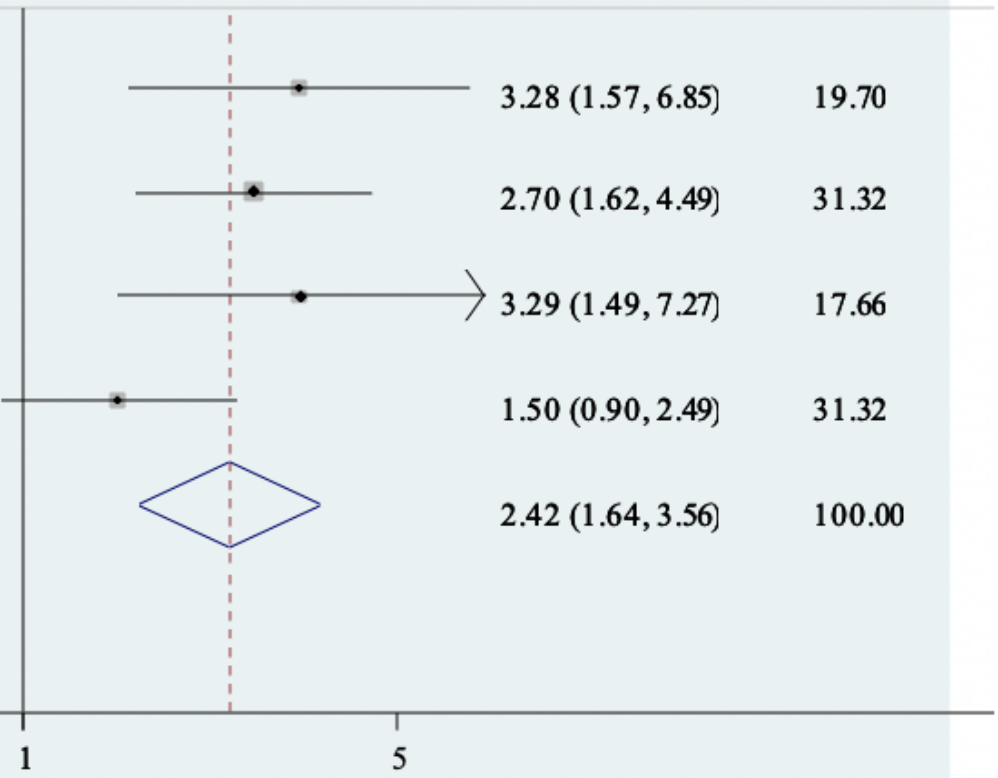

\section{Figure 7}

The association between G6PD deficiency and neonatal hyperbilirubinemia in studies from sub-Saharan Africa. 
Lake et al (2019)

Kassa et al. (2018,

Diala et al. $(2018$,

Emokpae et al. (2016)

Osuorah et al. (2018,

Overall (I-squared $=84.0 \%, \mathrm{p}=0.000)$

NOTE: Weights are from random effects analysis

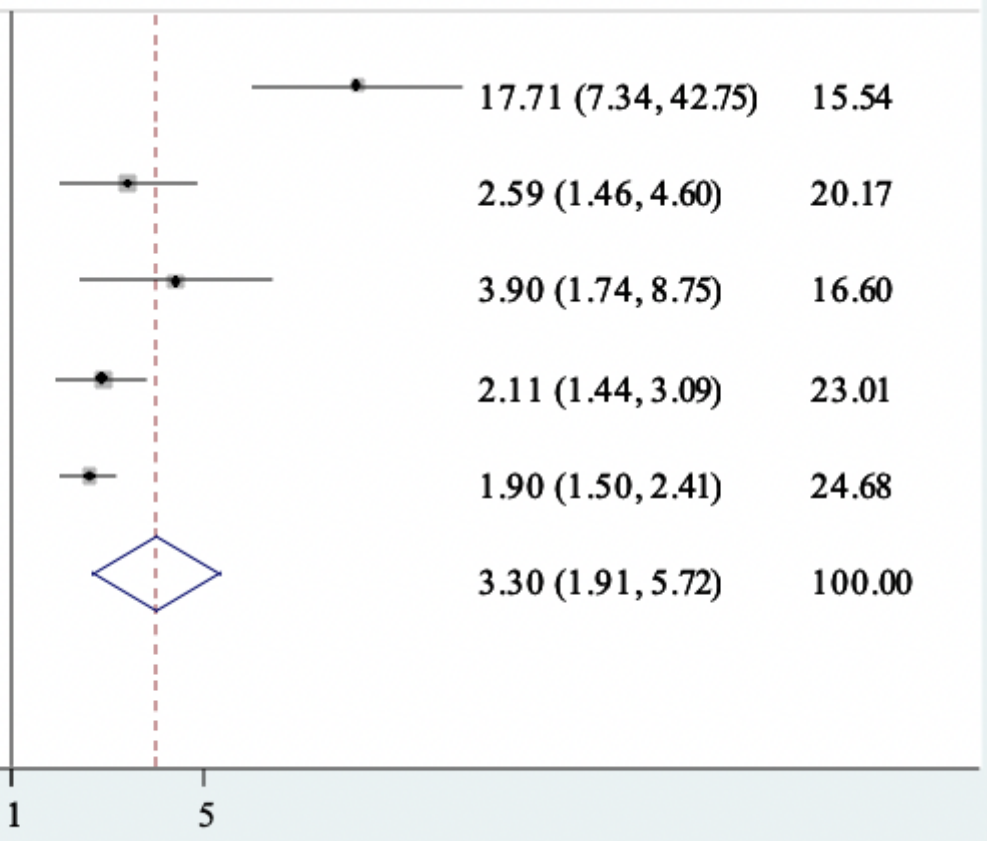

\section{Figure 8}

The association between blood type incompatibility and neonatal hyperbilirubinemia in studies involving sub-Saharan African populations. 